Voix et Images

volxetimages

\title{
Antonine Maillet : Attention! Les cordes-de-bois déboulent
}

\section{André Vanasse}

Volume 3, numéro 2, décembre 1977

Victor-Lévy Beaulieu

URI : https://id.erudit.org/iderudit/200109ar

DOI : https://doi.org/10.7202/200109ar

Aller au sommaire du numéro

\section{Éditeur(s)}

Les Presses de l'Université du Québec

\section{ISSN}

0318-9201 (imprimé)

1705-933X (numérique)

Découvrir la revue

Citer ce compte rendu

Vanasse, A. (1977). Compte rendu de [Antonine Maillet : Attention! Les cordes-de-bois déboulent]. Voix et Images, 3(2), 321-322.

https://doi.org/10.7202/200109ar d'utilisation que vous pouvez consulter en ligne.

https://apropos.erudit.org/fr/usagers/politique-dutilisation/ 


\section{Antonine Maillet: Attention! Les cordes-de-bois déboulent ${ }^{1}$}

Les gens du Pont, ceux d'en-bas, l'ont toujours appelée la Bessoune. Avait-elle une scour jumelle? D'aucuns disent que oui, d'autres lancent avec assurance un "nan-nan-nan " catégorique. Tout ce que l'on peut savoir avec certitude (et pourtant personne n'a pu le vérifier!) c'est qu'elle était née «avec l'étoile au derrière", ce qui la plaçait d'emblée au-dessus du septième fils né du septième fils dans la hiérarchie des êtres prédestinés.

On comprend pourquoi Antonine Maillet nous invite à nous délecter d'une autre page de sa chronique (commencée en 1958 avec Pointe-auxcoques): la Bessoune, fille de la Piroune, elle-même descendante du Mercenaire des Cordes-de-bois, mérite bien son titre d'héroïne.

Toujours avec la même truculence, s'enquérant auprès d'Ozite la centenaire, de Pierre à Tom, de Thaddée à Lovis, c'est-à-dire de tous les "conteurs-colporteurs-défricheteux d'histoires" (p. 17) de la place, Antonine Maillet, un peu à la façon d'un reporter, cherche «à débrouiller les fils d'une histoire nouée par tant de mépris, haine, colère, et chicanes épiques entre deux clans d'un même pays" (p. 13). Elle y parvient à merveille, tirant les vers du nez aux uns et aux autres, interprétant les heu!, les hé! hé! ou les outch! comme des aveux évidents, rendant les silences aussi sonores que s'il s'agissait de longues confessions, refusant la parole à l'un pour éviter une version apocryphe, nouant les fils par de solides nœuds marins pour finalement dessiner une très belle fresque de l'Acadie des années trente.

De fait entre les gens d'en-bas (ceux du Pont) et les gens de la butte (ceux des Cordes-de-bois) la lutte est féroce et prend des proportions démesurées. A-t-on idée de bouleverser tout le village en osant apposer des volets qui ne fonctionnent même pas à des fenêtres qui n'en ont que faire dans ce pays sans soleil ? lci les microbes créent l'épouvante: ils sont toujours porteurs de la peste et provoquent d'effroyables catastrophes. Voilà pourquoi, quand la Bessoune traverse le village de sa démarche fière et sensuelle, elle pose un geste aussi lourd de conséquences que le prétexte qui a permis de déclencher la première guerre mondiale. Car à «elle seule, la forlaque remplit le ciel et cache l'horizon" (p. 146); son vingt pouces de taille «bouch(e) la vue sur le monde" (p. 146).

II serait donc difficile de raconter, quand on n'a pas le talent d'Antonine Maillet, les menus faits qui alimentent cette chronique. Qu'il nous suf- 
fise de dire qu'entre les deux clans, deux conceptions de la vie s'opposent: celle des bien-pensants représentés (même s'ils sont, plus souvent qu'autrement, en désaccord) par Ma-Tante-la-Veuve, le Curé, MacFarlane, qui se frotte à celle des mécréants c'est-à-dire ceux du clan de la Piroune et plus tard de la Bessoune. L'ordre établi avec sa batterie d'hypocrisies veut écraser les tenants de la liberté et de l'anarchie.

La lutte est âpre. Les coups bas pleuvent des deux côtés. Personne finalement n'y gagne sauf le lecteur qui regrette un pou que le vicaire ait préféré Rome à la Bessoune (les lois à cette époque étaient infiniment plus strictes que de nos jours) obligeant la paurre à continuer, sans lui, le combat.

- Mais on n'en verra donc jamais la fin, de ceux-là! Jamais. (p. 350-351)

André Vanasse

1. Les Cordes-de-bois, Montréal, Leméac, «Roman québécois », 1977, 351 pages. 